\title{
Paródia e carnavalização: uma leitura do conto Adão e Eva, de Machado de Assis
}

\author{
Parody and carnivalization: a reading of the short \\ story Adão e Eva, by Machado de Assis
}

Rosilda de Moraes Bergamasco*

Resumo: Este artigo apresenta inicialmente uma breve reflexão teórica sobre a concepção de carnavalização da literatura - de acordo com a teoria bakhtiniana -, segundo a qual o carnaval, mesmo não sendo um fenômeno literário, e sim um conjunto de festividades de cunho carnavalesco, cria toda uma linguagem de formas concreto-sensoriais simbólicas que é suscetível de transposição para a linguagem da literatura. Na sequência, analisa-se o conto Adão e Eva, de Machado de Assis (2008), cujas características remetem a peculiaridades dos gêneros literários da Antiguidade clássica, como a sátira menipeia, que está impregnada de uma profunda cosmovisão carnavalesca, fazendo com que elementos opostos se combinem e se desviem da sua ordem habitual, mostrando desse modo, uma posição ideológica do autor.

Palavras-chave: Machado de Assis. Sátira menipeia. Carnavalização. Teoria bakhtiniana.

Abstract: This article presents a brief theoretical reflection about the conception of carnivalization in literature - according to Bakhtin's theory - carnival is not a literary phenomenon, but a set of imprint carnival festivities that creates a whole language with sensory-specific symbolic forms that can be transposed into the language of literature. The article analyzes the short story Adão e Eva by Machado de Assis (2008), whose characteristics refer to peculiarities of literary genres from classical antiquity, as Menippus satire, which is impregnated with a deep carnivalesque worldview, making opposite elements match up and deviate from their usual order, thus showing an ideological position of the author.

Keywords: Machado de Assis. Menippean satire. Carnivalization. Bakhtinian theory.

\section{Considerações Iniciais}

O carnaval, concebido como o conjunto de festejos de tipo carnavalesco, teve grande importância e ocupava um imenso espaço na vida das massas populares da Antiguidade grega e romana, cujo festejo principal, de cunho carnavalesco, eram as saturnais. Desse período até a Idade Média, a influência exercida por tais festejos só fez se ampliar, sendo que quase todas as

\footnotetext{
" Mestra em Estudos Literários. Universidade Estadual de Maringá - UEM. E-mail: <rosilda.demoraes@gmail.com>
} 
festas religiosas possuíam sua essência carnavalesca, bem como as festividades nacionais, os dias de feira, as festas da colheita da uva, as representações dos milagres, mistérios, a vida do teatro e os espetáculos, do mesmo modo, demonstravam esse caráter.

Também a literatura do riso e da paródia da época, de algum modo, se associava ao carnaval. Ou seja, o carnaval estava presente na vida das pessoas de uma forma bastante intensa, e durante alguns períodos do ano cada um poderia vivenciar outra vida, totalmente oposta à que levava oficialmente, como se fosse uma válvula de escape, quando, então, as massas populares poderiam se libertar das leis moralizantes e hierárquicas que regiam a sociedade da época. De acordo com Bakhtin (2002, p.129):

[...] pode-se dizer (com algumas ressalvas, evidentemente), que o homem medieval levava mais ou menos duas vidas: uma oficial, monoliticamente séria e sombria, subordinada à rigorosa ordem hierárquica, impregnada de medo, dogmatismo, devoção e piedade, e outra público-carnavalesca, livre, cheia de riso ambivalente, profanações de tudo que é sagrado, descidas e indecências do contato familiar com tudo e com todos. E essas duas vidas eram legítimas, porém separadas por rigorosos limites temporais. (grifos do autor).

$\mathrm{Na}$ época do Renascimento, a vida carnavalesca domina todos os gêneros da literatura e desse modo ocorre uma intensa carnavalização de quase toda a literatura de ficção, em outras palavras, é nesse período que a vida carnavalesco-popular atinge o seu ápice. A partir desse período, do século XVII, inicia-se então o declínio desse tipo de vida. Com o desenvolvimento da cultura festivo-cortês da mascarada, em que predominam apenas elementos externos do carnaval, e mais tarde com os festejos e divertimentos, denominados linha da mascarada, em que há conservação de liberdades e reflexos distintos da cosmovisão carnavalesca, ocorre um deslocamento das formas carnavalescas da sua base popular.

Assim, mesmo havendo a utilização de alguns elementos carnavalescos nas festividades, a partir de então o antigo sentido e a riqueza dos símbolos e formas, o caráter popular do carnaval, acaba por se perder. Com as mudanças ocorridas no carnaval, o caráter de carnavalização da literatura da mesma forma é modificado. Se até então o carnaval fazia parte da vida das pessoas e a carnavalização tinha um caráter imediato, sendo esta uma determinante na formação e fundamentação do gênero das obras literárias, a partir 
dessas transformações o carnaval não representa mais uma fonte imediata de carnavalização e aumenta, desse modo, a influência da literatura anteriormente carnavalizada. É dessa forma que "a carnavalização se torna tradição genuinamente literária”. (BAKHTIN, 2002, p.131)

Naturalmente, nessa nova literatura que se desenvolve, os aspectos carnavalescos vão sofrer modificações e reinterpretações. Alguns gêneros no campo do sério-cômico apresentam fundamentos essencialmente carnavalescos, como, por exemplo, o "diálogo socrático", que se caracteriza por livres mésalliances de ideias e imagens e pela "ironia socrática" - riso carnavalesco reduzido. Outro exemplo são as lendas carnavalescas que se diferenciam das lendas heroicas pela humanização dos seus heróis. Esses exemplos se caracterizam também pelo caráter ambivalente com que são construídos. Para Bakhtin, é na menipeia que a natureza carnavalesca se manifesta de forma ainda mais evidente. De acordo com o autor, "suas camadas externas e o seu núcleo profundo são impregnados de carnavalização”. (BAKHTIN, 2002, p.133).

Dentro dessa tradição carnavalesca literária é que se insere o conto Adão e Eva, de Machado de Assis. O conto faz uma inversão da narrativa da criação do mundo, contida no texto bíblico. Nela, não é Deus que cria o mundo e o homem, mas sim o Diabo. Não há a presença do pecado, porém também não há humanidade. Considerando a constituição do texto, evidenciaremos as categorias e as ações carnavalescas presentes na obra, bem como procuramos demonstrar que este conto pode ser considerado uma reinterpretação do gênero da sátira menipeia em termos de literatura moderna.

\section{As categorias e as ações carnavalescas presentes no conto}

O carnaval não é um fenômeno literário, mas sim uma "forma sincrética de espetáculo de caráter ritual, muito complexa, variada, que, sob base carnavalesca geral, apresenta diversos matizes e variações dependendo da diferença de épocas, povos e festejos particulares". (BAKHTIN, 2002, p.122). No entanto, toda a linguagem de formas concreto-sensoriais simbólicas criada pelo carnaval, mesmo não podendo ser traduzida para a linguagem verbal, é passível de transposição para a linguagem da literatura, numa operação denominada carnavalização da literatura.

Considerando que no carnaval todos participam ativamente de uma vida em que as leis, as normas, as restrições ou proibições ficam em suspenso, 
são revogadas, as categorias que vigoram durante esse momento têm como finalidade tornar iguais todos os homens. A primeira categoria carnavalesca $-o$ livre contato familiar entre os homens - tem como propósito eliminar toda e qualquer distância que possa existir entre homens, suspendendo assim qualquer espécie de desigualdade social. Conforme Bakhtin (2002, p.123):

Este é um momento muito importante da cosmovisão carnavalesca. Os homens, separados na vida por intransponíveis barreiras hierárquicas, entram em livre contato familiar na praça pública carnavalesca. Através dessa categoria do contato familiar, determina-se também o caráter especial da organização das ações de massas, determinando-se igualmente a livre gesticulação carnavalesca e o franco discurso carnavalesco.

No conto Adão e Eva, essa categoria pode ser notada na maneira como o enredo se desenrola. Primeiramente, quando o juiz de fora resolve contar a história da criação às avessas o padre carmelita pede para deixar em paz a Escritura e o juiz "desobedece" essa ordem.

- Deixemos em paz a Escritura, interrompeu o carmelita. Naturalmente, o Sr. Veloso conhece outros livros...

- Conheço o autêntico, insistiu o juiz de fora, recebendo o prato de doce que D. Leonor lhe oferecia, e estou pronto a dizer o que sei, se não mandam o contrário.

- Vá lá, diga. (ASSIS, 2008, p.360).

Desse modo, a hierarquia entre o sagrado e o profano se torna suspensa, bem como a hierarquia entre o padre e o juiz no que se refere a ter o poder ou o direito a falar sobre a Escritura. É através dos comportamentos, dos gestos e das palavras que o homem consegue se libertar do poder hierarquizante da vida extracarnavalesca. Consequentemente, com essas atitudes, ele se torna excêntrico e inoportuno sobre a ótica da lógica da vida não-carnavalizada.

É justamente essa característica que se ressalta na segunda categoria carnavalesca - a excentricidade. Ela diz respeito a "uma categoria específica da cosmovisão carnavalesca, organicamente relacionada com a categoria do contato familiar; ela permite que se revelem e se expressem - em forma concreto-sensorial - os aspectos ocultos da natureza humana" (BAKHTIN, 2002, p.123). No conto, essa característica excêntrica fica bem nítida no personagem do juiz de fora. Ao ser perguntado sobre a origem da curiosidade, se esta cabia a Adão ou a Eva, o juiz surpreende a todos: 
Consultado, o juiz de fora respondeu que não havia matéria para opinião; porque as coisas no paraíso terrestre passaram-se de modo diferente do que está contado no primeiro livro do Pentateuco, que é apócrifo. Espanto geral, riso do carmelita, que conhecia o juiz de fora como um dos mais piedosos sujeitos da cidade, e sabia que era também jovial e inventivo, e até amigo da pulha, uma vez que fosse curial e delicada; nas coisas graves, era gravíssimo. (ASSIS, 2008, p.359).

Ao declarar que a história da criação se deu de forma distinta da contada na Bíblia, um aspecto da sua personalidade até então desconhecido se revela. Tido pelo padre como uma pessoa piedosa, ao subverter os escritos sagrados a excentricidade se mostra bem evidente.

A terceira categoria - as mésalliances carnavalescas - procura aproximar, combinar elementos contrários, como sagrado/profano, elevado/baixo, grande/insignificante, sábio/tolo. Dessa forma relaciona-se diretamente com a primeira categoria - a familiarização - que quebra com todas as distâncias hierárquicas. No conto, as mésalliances permeiam a narrativa, a combinação dos elementos contrários aparece em vários momentos. Como por exemplo, na reunião de Deus e o Diabo na criação do mundo:

E a ação divina mostrou-se logo porque, tendo o Tinhoso criado as trevas, Deus criou a luz, e assim se fez o primeiro dia. No segundo dia, em que foram criadas as águas, nasceram as tempestades e os furacões; mas as brisas da tarde baixaram do pensamento divino. No terceiro dia foi feita a terra, e brotaram dela os vegetais, mas só os vegetais sem fruto nem flor, os espinhosos, as ervas que matam como a cicuta; Deus, porém, criou as frutas frutíferas e os vegetais que nutrem ou encantam. E tendo o Tinhoso cavado abismos e cavernas na terra, Deus fez o sol, a lua e as estrelas; tal foi a obra do quarto dia. (idem, p.360, grifos nossos).

A quarta categoria carnavalesca - a profanação - refere-se diretamente à terceira, pois ao combinar, aproximar elementos contrários, essa junção não se dá de forma lógica em relação à realidade extracarnavalesca. A profanação buscará inverter ou relativizar a distância entre esses elementos, a fim de retirar ou criticar os poderes dominantes na sociedade. Para Bakhtin (2002, p.123), esta categoria:

[...] é formada pelos sacrilégios carnavalescos, por todo um sistema de descidas e aterrissagens carnavalescas, pelas indecências carnavalescas, 
relacionadas com a força produtora da terra e do corpo, e pelas paródias carnavalescas dos textos sagrados e sentenças bíblicas, etc.

Assim sendo, no conto Adão e Eva o primeiro indício de profanação acontece desde a composição da obra, pois se trata de uma paródia de um texto bíblico. Em alguns momentos do enredo também pode ser notada a ocorrência da profanação, como, por exemplo, quando o juiz de fora, ao ser consultado sobre a origem da curiosidade, deixa todos espantados ao afirmar que a história da criação se deu de forma diferente da contada na Escritura, chegando a dizer que o primeiro livro do Pentateuco é apócrifo, ou seja, não reconhecido pela Igreja como livro sagrado. E mais, que ele conhece o livro autêntico e pretende contar como se deu realmente a criação. Com essas declarações, Veloso põe em dúvida a autenticidade de um livro considerado sagrado pela Igreja, ou seja, o sagrado torna-se profano enquanto que o livro considerado "autêntico" pelo juiz é elevado à condição de sagrado.

Outro momento que pode ser considerado como uma profanação é a inversão dos elementos contrários, já que não é mais Deus que cria o mundo e o homem, mas sim o Diabo. Desse modo, acontece, a elevação do personagem mais baixo - o Diabo - e o rebaixamento do personagem mais alto - Deus - no que se refere ao poder atribuído a cada um.

- Aqui está como as coisas se passaram. Em primeiro lugar, não foi Deus que criou o mundo, foi o Diabo...

- Cruz! exclamaram as senhoras. (ASSIS, 2008, p. 360).

As categorias carnavalescas exerceram grande influência na literatura no que se refere à forma e a formação dos gêneros. Em especial, a categoria de livre familiarização do homem com o mundo tem sido transposta para a literatura e contribui para destruição das distâncias entre épica e trágica, bem como demonstra a posição do autor em relação aos heróis da trama e isso se manifesta claramente na menipeia.

Além das categorias, o carnaval engloba também ações carnavalescas. A primeira delas é a coroação bufa e o posterior destronamento do rei do carnaval. Essa ação pode ser constatada em todos os festejos de tipo carnavalesco e é nela que repousa o fundamento do carnaval: a ênfase das mudanças e transformações, da morte e da renovação. Por isso mesmo, esse ritual é ambivalente, biunívoco, pois nele ocorre a coroação de um bobo ou escravo como forma de inaugurar a nova vida que se instaura, a carnavalesca. Ao mesmo tempo, 
nessa coroação já está contido o seu contrário - o destronamento desse novo rei - como maneira de mostrar que o carnaval está acima das mudanças e não tem intenção de modificar, mas relativizar tudo.

No conto, esse ritual de coroação ocorre quando o juiz declara que não foi Deus quem criou o mundo e sim o Diabo, ou seja, ele destitui Deus de seu poder absoluto e "coroa" o Diabo como o construtor da obra. Com essa inversão da história da criação o mundo carnavalizado é inaugurado. Por outro lado, o destronamento se dá quando após o Diabo tentar, inutilmente, fazer Adão e Eva pecarem e perderem o paraíso, Deus em recompensa pela relutância do casal em se manterem firmes e obedientes ao seu Senhor, resolve levá-los para junto de si, destituindo, desse modo, o poder que até então o Diabo procurava exercer sobre a Terra e sobre os homens.

Também as imagens carnavalescas possuem uma natureza ambivalente, pois ao mesmo que tempo que expressam um significado, dentro dele já contém o seu contrário. Especialmente a imagem do fogo é bastante representativa, considerando que no carnaval o fogo significa tanto a destruição quanto a renovação do mundo. O riso carnavalesco é extremamente ambivalente, utilizado como forma de reagir às crises, principalmente às da vida da divindade, do universo e do homem. Assim, o riso abrange os dois polos da mudança - morte/renascimento, negação/afirmação.

\section{A sátira menipeia e o conto}

No século V a. C. as farsas já recebiam a denominação de comédia, apresentando como característica principal a preferência pela poesia satírica - em que o espírito mordaz e sarcástico predomina com ataques a figuras conhecidas da sociedade, sendo conhecida como Comédia Antiga. A partir do século III a. C. surge também a comédia de costumes ou Comédia Nova, que abrange fatos corriqueiros ocorridos no dia a dia do homem comum. A sátira teve origem com os gregos, mas é com os romanos que seu prestígio se acentua. Carvalho (2008, p. 48-49), ao levar em conta o significado etimológico da palavra sátira, sintetiza que:

[...] a sátira pode ser compreendida como um prato cheio de muitas variedades de frutas que os antigos ofereciam aos deuses à época das festas da colheita. Sendo, pois, assim, tais festas relacionadas ao folclore, semelhante a muitas outras festividades, dentre elas, o carnaval, o qual, também se faz presente em muitas situações satíricas. 
Essa forma de conceber a sátira demonstra a relação entre as festividades populares e a literatura da época, as quais possuíam como característica comum a mistura de elementos antagônicos como sagrado e profano, sublime e grotesco. Dessa mistura surge o gênero denominado sátira menipeia, que é caracterizado, sobretudo, pela denúncia, pela apresentação de uma linguagem mais coloquial, popular e temas muitas vezes ridicularizantes, vergonhosos ou grosseiros, ou seja, um verdadeiro prato cheio para o divertimento de alguns e condenação de outros.

O primeiro a nomear a expressão Saturae Menippeae é Terêncio (116 a 27 a. C.). Quanto ao adjetivo menippeae, está associado ao nome de Menippus, filósofo grego, que fez parte da escola dos cínicos, no século III a. C. Segundo Carvalho (2008, p.47), "esta escola, em função da completa independência, despreza a riqueza, as convenções sociais, e obedece, exclusivamente, às leis da natureza". Dessa forma, os escritores que faziam parte desta escola possuíam plena liberdade e autonomia para falar sobre as injustiças, as deficiências sociais ou a corrupção dos poderosos.

Assim, desde sua origem grega, seu posterior desenvolvimento entre os romanos e até os dias atuais, o gênero literário da sátira menipeia tem sido largamente utilizado pelos mais diversos escritores, nas mais diferentes épocas e nações, como modo de realizar críticas à sociedade ou a determinado poder dominante de uma época. Mais que isso, esse gênero, com sua capacidade de mudar sua forma, foi capaz de se desdobrar e se combinar com outros gêneros, como o romance grego e grego antigo. (BAKHTIN, 2002, p.136). Na Idade Média, a menipeia se renova e "vive em formas mais livres e originais em gêneros dialogados e carnavalizados [...] como as 'discussões', os 'debates' e as 'glorificações' ambivalentes [...], a moralidade e os milagres e, na Idade Média tardia, os mistérios e sotas”. (BAKHTIN, 2002, p.136)

No Renascimento grande parte da literatura está impregnada de elementos da menipeia carnavalizada. Já na Idade Moderna a introdução de elementos característicos da menipeia vem acompanhada de diferentes níveis de evolução e de denominações. Cumpre salientar que na literatura moderna, a menipeia é "acompanhante predominante das formas mais condensadas e vivas da carnavalização" (BAKHTIN, 2002, p.137), como, por exemplo, os contos.

Para Bakhtin (2002, p.133), algumas menipeias representam diretamente os festejos carnavalescos, especialmente aquelas que apresentam a carnavalização dos três planos: do Olimpo, do Inferno e da Terra, ou seja, com 
a ocorrência da livre familiarização, dos escândalos, das excentricidades, das mésalliances e a coroação-destronamento.

No conto, a carnavalização pode ser percebida nos três planos: no Céu - Deus é destituído do seu poder supremo de criador do mundo, relegado ao cargo de somente "corrigir ou atenuar a obra" do Tinhoso; no Inferno - o Tinhoso é elevado a criador do mundo e dos homens; na Terra - Adão e Eva não são pecadores, desobedientes das ordens divinas e por isso são elevados ao paraíso celeste.

É comum também o que Bakhtin (2002, p.133) chamou de “experimentação moral e psicológica" em que se revelam como, por exemplo, a dupla personalidade, os sonhos, as obsessões, as fantasias. No conto, pode ser observada a dupla personalidade do personagem Veloso - juiz de fora - que considerado, pelo padre, uma pessoa das mais piedosas da cidade, ou seja, temente a Deus, religiosa, resolve contar uma nova versão da história da criação do mundo. De tal modo que outra personalidade do juiz é revelada, não mais piedosa como concebida pelo padre, mas, de certa forma, contrária aos dogmas da Igreja Católica.

Uma das singularidades da menipeia é o peso do elemento cômico que pode variar para mais ou para menos dentro do texto, a critério do autor. No conto, o elemento cômico aparece várias vezes, como, por exemplo, quando há a descrição das atitudes de Adão e Eva na relação de um com o outro, antes de Deus infundir-lhes a alma:

Adão e Eva ouviram submissos; e ficando sós, olharam um para o outro, admirados; não pareciam os mesmos. Eva, antes que Deus the infundisse os bons sentimentos, cogitava de armar um laço a Adão, e Adão tinha ímpetos de espancá-la. (ASSIS, 2008, p.361).

Nota-se também nesse trecho a presença de cenas da vida real, com a representação naturalista dos fatos. Outra característica desse gênero é a liberdade filosófica e de construção do enredo, sem preocupação com a verossimilhança, e adição de aspectos da fantasia ou do fantástico. Exemplo disso se dá na completa subversão do texto bíblico, ou seja, é criada outra versão da história com elementos fantasiosos e provindas da imaginação:

E logo o arcanjo, pondo na cabeça o elmo de diamante, que rutila como um milhar de sóis, rasgou instantaneamente os ares, chegou a Adão e Eva, e disse-lhes: 
- Salve, Adão e Eva. Vinde comigo para o paraíso, que merecestes pela repulsa às instigações do Tinhoso.

Um e outro, atônitos e confusos, curvaram o colo em sinal de obediência; então Gabriel deu as mãos a ambos, e os três subiram até à estância eterna, onde miríades de anjos os esperavam [...]. (idem, p.363).

De acordo com Bakhtin (2002, p.127), "a paródia é um elemento inseparável da "sátira menipeia" e de todos os gêneros carnavalizados." Isso porque, desde a Antiguidade, a paródia esteve articulada à cosmovisão carnavalesca, pois possui um caráter ambivalente considerando que ao parodiar se cria o duplo destronante, o "mundo às avessas", sendo utilizada principalmente no aspecto cômico tanto do riso fúnebre quanto do triunfal.

A paródia é um termo que se tornou institucionalizado a partir do século XVII e pode ser considerada uma nova forma de representação literária, já que faz parte de um novo gênero - a comédia, no qual os homens ou os deuses não são mais enaltecidos, mas sim rebaixados. Mas já em Aristóteles aparecem comentários sobre a paródia:

Em sua Poética atribuiu a origem da paródia, como arte, a Hegemon de Thaso (séc. 5 a. C.), porque ele usou o estilo épico para representar os homens não como superiores ao que são na vida diária, mas como inferiores. Teria ocorrido, então, uma inversão. A epopeia, gênero que na Antiguidade servia para apresentar os heróis nacionais no mesmo nível dos deuses, sofria agora uma degradação. Essa observação de Aristóteles revela um enfoque marcadamente ético e mostra que os gêneros literários eram tão estratificados quanto as classes sociais. A tragédia e a epopeia eram gêneros reservados a descrições mais nobres, enquanto a comédia era o espaço da representação popular. (SANT'ANNA, 2003, p.11)

Como afirma Bakhtin (2002, p. 127), "na Idade Média, sob a cobertura da liberdade legalizada do riso, era possível a paródia sacra, ou seja, a paródia dos textos e rituais sagrados". Oliver (2008, p.165-6) expressa que a paródia é uma:

[...] forma de solapar o mito em sua credibilidade. Vista sob o ponto de vista da sátira menipeia, a mitologia greco-romana ou judaico-cristã constituiu um repositório de ideias recebidas e preservadas de forma intocável. No caso da mitologia judaico-cristã, esse repositório é, além do mais, inquestionável, pois seus mantenedores são religiosos que tendem a interpretar a Bíblia não como literatura mas como revelação. 
No conto Adão e Eva, Machado de Assis faz exatamente isso - uma paródia de um texto sagrado a fim de demonstrar a ambivalência existente nos elementos opostos. Se por um lado na paródia contada pelo juiz o homem não comete o pecado original, por outro, como consequência, não há esperança por parte deles em habitar o mundo em que estavam inseridos, ou seja, não se tornam humanos e sim anjos.

Através dessa paródia do texto bíblico, o autor procura fazer uma crítica à instituição da Igreja Católica, pois contraria a Igreja que, ao contar sobre a criação do mundo, coloca Adão e Eva como pecadores e culpados pela perda do paraíso terrestre. Ao subverter a história da criação, demonstrando que o pecado de Adão e Eva foi benéfico para a humanidade, pois do contrário não haveria habitação humana no mundo, mostra a presença de elementos da sátira menipeia, como profanação de escritos sagrados, elevação das características humanas sobre as divinas:

- Pensando bem, creio que nada disso aconteceu; mas também, D. Leonor, se tivesse acontecido, não estaríamos aqui saboreando este doce, que está, na verdade, uma coisa primorosa. É ainda aquela sua antiga doceira de Itapagipe? (ASSIS, 2008, p.364).

A relação entre paródia e carnavalização no que se refere à ambivalência entre morte e renovação também pode ser notada nesse conto. Ao parodiar um episódio da Escritura, há a pretensão de fazer morrer conceitos predeterminados, institucionalizados, de que o pecado somente traz morte aos seres humanos e, a partir disso, mostrar uma nova perspectiva de uma mesma história, uma nova forma de ver e compreender esse fato. Afinal, "o riso carnavalesco também está dirigido contra o supremo; para a mudança dos poderes e verdades, para a mudança da ordem mundial”. (BAKHTIN, 2002, p.127).

\section{Considerações Finais}

A leitura do conto Adão e Eva, de Machado de Assis, sob a perspectiva da teoria bakhtiniana referente à carnavalização da literatura, tornou possível uma maior percepção e compreensão de como se dá a transposição da linguagem carnavalesca para a linguagem literária. A aplicação dos conceitos relacionados às categorias e as ações carnavalescas ao texto demonstram que todas as categorias e ações encontram-se relacionadas umas às outras e são 
fundamentais para o entendimento do "mundo às avessas" que a cosmovisão carnavalesca contempla.

Ao evidenciar a presença das categorias e ações carnavalescas dentro do conto, procurou-se demonstrar como a riqueza do carnaval, na sua essência e nos seus valores, é resgatada e exerce grande influência sobre a literatura até os dias atuais, especialmente nessa forma condensada de escrita, que é o conto, e pode ser considerado um importante aporte para a ocorrência da carnavalização.

É importante ressaltar que cada uma das categorias e ações não são meramente conceitos abstratos, mas sim formas concreto-sensoriais vivenciáveis e as transposições ao texto literário implicam em imagens artísticas que podem ser evidenciadas através de vários elementos textuais como, por exemplo, o discurso dos personagens e/ou do narrador, o comportamento e as atitudes dos personagens.

Essas são imagens que revelam como os elementos carnavalescos podem ser modificados e reinterpretados na literatura moderna. Em específico, no conto Adão e Eva a releitura desses elementos demonstra algumas formas de se inverter a ordem habitual da vida extracarnavalesca, bem como a inauguração e instauração da vida carnavalesca através da inversão da história da criação do mundo contada nas Escrituras.

A nova versão da criação do mundo sugerida no conto configura-se como uma paródia de um texto sagrado - a Bíblia - e está associada diretamente ao gênero da sátira menipeia, pois representa um elemento inseparável deste gênero. Afinal, a paródia está diretamente associada à cosmovisão carnavalesca, pois proporciona a possibilidade de um mesmo fato ou acontecimento ser visto, percebido, por mais de um ponto vista e, desse modo, revela posicionamentos estéticos e ideológicos do autor.

Isso porque, ao utilizar a paródia como principal elemento da menipeia, Machado procura fazer críticas à instituição da Igreja Católica, pois, através da paródia, é possível converter uma estrutura fechada em outra aberta, dando ao texto-fonte outra dimensão, com a incidência de enfoques deformativos e irônicos. Ao distorcer o sentido original do texto sagrado, o autor procura lançar um novo olhar sobre um acontecimento institucionalizado e sacralizado, configurando assim uma releitura da antiga sátira menipeia. 


\section{Referências}

ASSIS, M. de. Adão e Eva. In: 50 Contos. 6. reimp. São Paulo: Companhia das Letras, 2009. p. 359-364.

BAKHTIN, M. Problemas da poética de Dostoiévski. 3. ed. Rio de Janeiro: Forense Universitária, 2002.

CARVALHO, W. de. A sátira menipeia no contexto da Revolução de Abril: Alexandra Alpha, de José Cardoso Pires. Dissertação de Mestrado em Letras Vernáculas - Literatura Portuguesa. Faculdade de Letras. Universidade Federal do Rio de Janeiro, Rio de Janeiro, maio, 2008, $150 \mathrm{p}$.

OLIVER, É. V. Rabelais e Joyce: três leituras menipeias. São Paulo: Ateliê Editorial, 2008. SANT’ANNA, Affonso Romano de. Paródia, paráfrase e Cia. 7. ed. São Paulo: Ática, 2003.

Recebido para publicação em 16 de agosto de 2011. Aceito para publicação em 23 de novembro de 2011. 